\title{
Ações de Humanização do Núcleo de Pesquisa Clínica de um Hospital Público de São Paulo Especializado no Tratamento do Câncer.
}

\author{
Longo, Elaine de Santana; Fiuza, Mariana Nigro; Matias, Fabiane; Sponton, Maria \\ Helena da Cruz; Riechelmann, Rachel S.Pimenta; Arai, Roberto Jun \\ Instituto do Câncer do Estado de São Paulo - elainesle@yahoo.com.br
}

Introdução: um Hospital Público de São Paulo, especializado no tratamento do câncer visa contribuir com a saúde e a qualidade de vida da sociedade, sendo atualmente referência para o Estado de São Paulo. um dos pilares para execução de suas atividades é o atendimento humanizado, amparado pela Política Nacional de Humanização. o setor Núcleo de Pesquisa Clínica deste hospital oferece alternativas promissoras de tratamento que ainda estão em desenvolvimento. Os projetos de pesquisa são nacionais e multinacionais e produzem conhecimento científico para a área oncológica. para garantir que o paciente inserido em condições de pesquisa clinica tenha atendimento humanizado, o Núcleo de Pesquisa Clínica buscou ações e implementação de projetos. Objetivo: Relatar as ações de Humanização do Núcleo de Pesquisa Clínica. Método: Mapeamento das ações de humanização adotadas nos protocolos gerenciados pelo Núcleo de Pesquisa Clínica. Resultados: As ações do Núcleo de Pesquisa incluem: 1. Revisão do texto do termo de consentimento livre esclarecido que é oferecido ao voluntário para leitura antes da tomada de decisão de sua participação no projeto de pesquisa. Esta ação visa garantir que a linguagem esteja acessível aos pacientes, respeitando a legislação vigente e heterogeneidade cultural; 2. Realização do atendimento de enfermagem baseado no modelo assistencial Primary Nurse, no qual o Enfermeiro Referência tem o intuito de gerar um vínculo com o voluntário para realização dos procedimentos assistenciais, esclarecimento de dúvidas ou reporte de eventualidades e, sobretudo, para que este seja realizado com segurança por equipe treinada especificamente para o projeto em cada especialidade médica; 3 . Orientação a todos os pacientes descontinuados dos projetos de pesquisa sobre este processo, novos fluxos e profissionais de referência que serão disponibilizados para continuidade do atendimento, oferecendo informações para que o paciente mantenha-se atualizado e mantido em acolhimento dentro da Instituição; 4. Manutenção do conceito de que os pacientes da instituição devem possuir tratamento semelhante, mesmo que participando de projetos de pesquisa que exigem acompanhamento diferenciado e específico. Conclusão: As ações de Humanização do Núcleo de Pesquisa Clínica têm o intuito de manter o paciente inserido dentro de um projeto de pesquisa em atendimento humanizado, para minimizar possíveis estressores desde a fase de consentimento e inclusão, durante toda a sua participação no projeto até a sua descontinuação. o reforço e manutenção das informações fornecidas aos voluntários possuem papel crítico para evitar a insegurança dos participantes dentro dos procedimentos requeridos pela Instituição, tanto relacionados ao atendimento gerenciado pelo setor Núcleo de Pesquisa Clínica quanto de outras áreas.

Longo, Elaine de Santana; Fiuza, Mariana Nigro; Matias, Fabiane; Sponton, Maria Helena da Cruz; Riechelmann, Rachel S.Pimenta; Arai, Roberto Jun. Ações de Humanização do Núcleo de Pesquisa Clínica de um Hospital Público de São Paulo Especializado no Tratamento do Câncer.. In: Anais do Congresso Internacional de Humanidades \& Humanização em Saúde [= Blucher Medical Proceedings, num.2, vol.1]. São Paulo: Editora Blucher, 2014. ISSN 23577282

DOI 10.5151/medpro-cihhs-10310 